\title{
Prevenção à violência contra a criança e o adolescente sob a ótica da saúde: um estudo bibliográfico
}

\author{
Prevention of violence against the child and \\ the adolescent under the view of the health: \\ a bibliographical study
}

Romeu Gomes 1

Cosme Marcelo Furtado Passos da Silva 2

Kathie Njaine 2

\footnotetext{
1 Instituto Fernandes Figueira-Fiocruz, Av. Rui Barbosa 716, 40 andar, 22250-020 Rio de Janeiro, RJ, Brasil

romeu@iff.fiocruz.br

2 Centro Latino Americano de Estudos de Violência e Saúde "Jorge Careli", Departamento de Epidemiologia e Métodos Quantitativos em Saúde, Escola Nacional de Saúde Pública-Fiocruz, Av. Brasil 4036, sala 702, 21040-361 Rio de Janeiro, RJ, Brasil
}

\begin{abstract}
This work analyses the proposals of prevention of violence against children and adolescents, which are explicity or implicity indicated on articles published in national journals. The main objectives of this analysis are to identify the state of the art concerning this thematic and to subsidize health politics. Fortyeight articles published between January 1990 and July 1997 were selected for the analysis of the bibliography. This study is based on quantitative and qualitative approaches. The results point out that domestic violence prevails among all the kinds of violence identified (25\%); the literature review is the most used methodology (45.8\%) and the area of the pediatrics concentrates the largest production (37.5\%). This paper argues that the authors do not reduce the discussion to medicalization, in fact, they search for an understanding of the multicasuality of violence which does not reduce it to an individual issue. In addittion to that, they propose an interdisciplinary approach to prevention of violence.
\end{abstract}

Key words Prevention of Violence; Child; Adolescent; Bibliographical Study
Resumo Este trabalho tem como objetivo analisar as propostas de prevenção da violência contra crianças e adolescentes, indicadas de formas explícita ou implícita em artigos publicados em periódicos nacionais, com vistas a estabelecer um panorama do estado da arte acerca da temática em questão, bem como fornecer subsídios que possam servir às políticas de saúde. A metodologia consiste de uma pesquisa bibliográfica, com 48 artigos publicados no período de janeiro de 1990 a julho de 1997. A análise baseia-se em princípios de investigação quantitativos e qualitativos. Os resultados revelam que a violência doméstica predomina entre os tipos de violência encontrados (25\%); a revisão bibliográfica é o desenho metodológico mais utilizado $(45,8 \%)$ e área da pediatria detém a maior produção (37,5\%). Entre as conclusões, constata-se que os autores evitam cair na armadilha da medicalização do problema, pleiteando uma compreensão da multicausalidade da violência e não a reduzindo ao plano do indivíduo, e propõem que se adote um trabalho interdisciplinar no campo da prevenção.

Palavras-chave Prevenção da Violência; Criança; Adolescente; Estudo Bibliográfico 


\section{Introdução}

Este artigo é parte de uma pesquisa que vem analisando a produção acadêmica no campo da saúde, cujo objeto de reflexão tenha sido a violência. $\mathrm{O}$ material bibliográfico selecionado refere-se ao período de 1990 ao primeiro semestre de 1997.

Especificamente este trabalho tem como objetivo analisar as propostas de prevenção da violência contra crianças e adolescentes, indicadas de forma explícita ou implícita em artigos publicados em periódicos nacionais, com vistas a estabelecer um panorama do estado da arte acerca da temática em questão, bem como fornecer subsídios que possam servir às políticas de saúde.

Com base em Leavell e Clark (1976) e Flitcraft (1993), entende-se, neste estudo, a prevenção em três níveis: primário, secundário e terciário. O primário compreende as ações voltadas para a sensibilização dos profissionais de saúde a respeito de medidas preventivas da violência para que possam atuar, no campo da educação e da informação, junto a pessoas, grupos e a comunidade em geral. O nível secundário se refere a formas de identificação, diagnóstico de casos e estratégias de intervenção precoce. Por fim, no terceiro nível incluem-se o atendimento de serviços hospitalares e institucionais-comunitários e a organização dos serviços de saúde, envolvendo maior grau de complexidade, a fim de adequar a atenção aos casos de violência em termos de tratamento e/ou reabilitação.

\section{Metodologia}

A metodologia adotada seguiu os princípios de pesquisa bibliográfica, envolvendo as atividades básicas de identificação, compilação e fichamento das fontes localizadas através de bases de consulta (Lilacs, Medline, Adolec, Ibict) e fichas catalográficas de instituiçõos visitadas no eixo Rio-São Paulo.

Na primeira fase foram coletados 101 artigos sobre violência em periódicos nacionais. Desse acervo foram identificadas 54 publicações cuja temática tratava da violência contra a criança e o adolescente. Essa parcela da produção reflete a preocupação dos profissionais com a questão da saúde da criança e do adolescente vitimizados pela violência em suas mais diferentes formas. Dessas 54 publicações analisadas, encontraram-se 48 artigos que abordavam, especificamente, princípios e formas de prevenção à violência, dos seguintes autores: Assis (1994a); Assis e Souza (1995); Barison (1992); Bitencourt (1995); Bucher et al. (1994); Campos et al. (1994); Cariola (1995); Castro (1993); Castro (1995); Centeville et al. (1997); Dalaneze (1996); Davoli e Ogido (1992); Deccache-Maia (1997); Del Ciampo e Ricco (1996); Del Ciampo et al. (1997); Deslandes (1994a); Farinatti (1992); Flores e Caminha. (1994); Fonseca (1992); Forster et al. (1992); Friedrich (1995); Godoi et al. (1991); Gomes (1994b, c, 1996); Gorgulho (1995); Guagliardi (1990); Lefèvre (1992, 1993); Lyra et al. (1996); Magalhães (1995); Marmo et al. (1995); Mello (1997); Menezes et al. (1996); Minayo (1990); Minayo e Assis (1993 e 1994); Neumann e Oliveira (1997); Nogueira (1994); Scivoletto et al. (1996, 1997); Seibel (1992); Siqueira et al. (1996); Souza e Assis (1996); Stubbe (1996); Sudbrack (1992); Sukiennik (1992); Zavasch (1991).

Foram utilizadas as seguintes categorias para a classificação inicial desse material: a área de produção; o tipo de violência; o desenho metodológico empregado; o nível de prevenção; o ano e o local de publicação.

A análise do material fundamentou-se na articulação das abordagens quantitativa e qualitativa, uma vez que essas duas perspectivas, de naturezas diferentes, são complementares na busca de melhor se aproximar de uma realidade que se quer conhecer (Minayo \& Sanches, 1993).

Os dados quantitativos analisados foram armazenados num banco de dados em Dbase III Plus, trabalhando-se com freqüências absolutas e relativas através do Programa EpiInfo 6.0. Após a integralização desse banco foi realizado cruzamento de variáveis através do mencionado programa.

Os dados qualitativos foram analisados através da Técnica de Análise de Conteúdo, modalidade Temática. A técnica de análise temática "consiste em descobrir os 'núcleos de sentido' que compõem a comunicação e cuja presença, ou freqüência de aparição podem significar alguma coisa para o objetivo analítico escolhido" (Bardin, 1979: 105). Além de se buscar respostas para questões, com essa técnica pode-se caminhar na direção da "descoberta do que está por trás dos conteúdos manifestos, indo além das aparências do que está sendo analisado"(Gomes, 1994a: 74). 
Para a análise dos núcleos de sentido, os artigos foram classificados segundo o tipo de violência cometido contra a criança e o adolescente.

\section{Discussão dos resultados}

\section{Aspectos gerais da produção analisada}

A análise revelou que a expressão prevenção, ou suas derivações, como prevenir, nem sempre é explicitada nos textos. No entanto, aprofundando mais a leitura, percebe-se que mesmo os autores que não citam essa expressão apontam, de forma implícita, princípios de prevenção. Do conjunto dos artigos, como pode ser visto na Figura 1, verificou-se que $52,1 \%$ não mencionam a palavra prevenção, enquanto $47,9 \%$ o fazem. Uma possível interpretação para isso se deve ao fato do que se entende por esse conceito. Comumente, a prevenção é explicitada quando se trata de ações educativas ou procedimentos realizados para que seja evitada a ocorrência de algum evento, demonstrando, segundo a classificação do presente artigo, apenas o nível primário.

Quanto aos níveis de prevenção, observouse que, nos 48 artigos, o primário foi o predominante com $41,7 \%$, seguido pelo secundário (25\%). Verificou-se também que 31,2\% da produção analisada contemplaram, de forma implícita ou explícita, mais de um nível de prevenção.

Ao relacionar as produções que referem prevenção com os níveis em que ela pode ocorrer, constatou-se que as que se voltam para os três níveis o fazem de forma direta, enquanto $80 \%$ das que abordam simultaneamente o nível primário e secundário o fazem de forma indireta.

Em relação aos tipos de violência cometidos contra a criança e o adolescente, o conteúdo da produção analisada, como pode ser visto na Tabela 1, aponta para uma diversidade desses tipos. Nesse conjunto, ressalta-se a presença da violência doméstica com $25 \%$. A proporção desse tipo de violência pode ser mais elevada se forem considerados os "abusos sexuais”, uma vez que parte desses abusos são cometidos por parentes.

Observou-se que em $83,3 \%$ dos artigos sobre drogas o conceito de prevenção foi diretamente mencionado. Verificou-se, por outro lado, que os artigos sobre afogamento, comportamento agressivo, delinqüência, homicídio e prostituição infanto-juvenil não fazem de forma clara propostas de prevenção.

Optou-se, num primeiro momento, por classificar de forma abrangente a metodologia dos estudos, não especificando os diferentes subtipos de desenho metodológico, uma vez que não foi esse o objetivo do presente tra-

Figura 1

Distribuição dos artigos segundo nível e explicitação de prevenção, 1990-1997*.

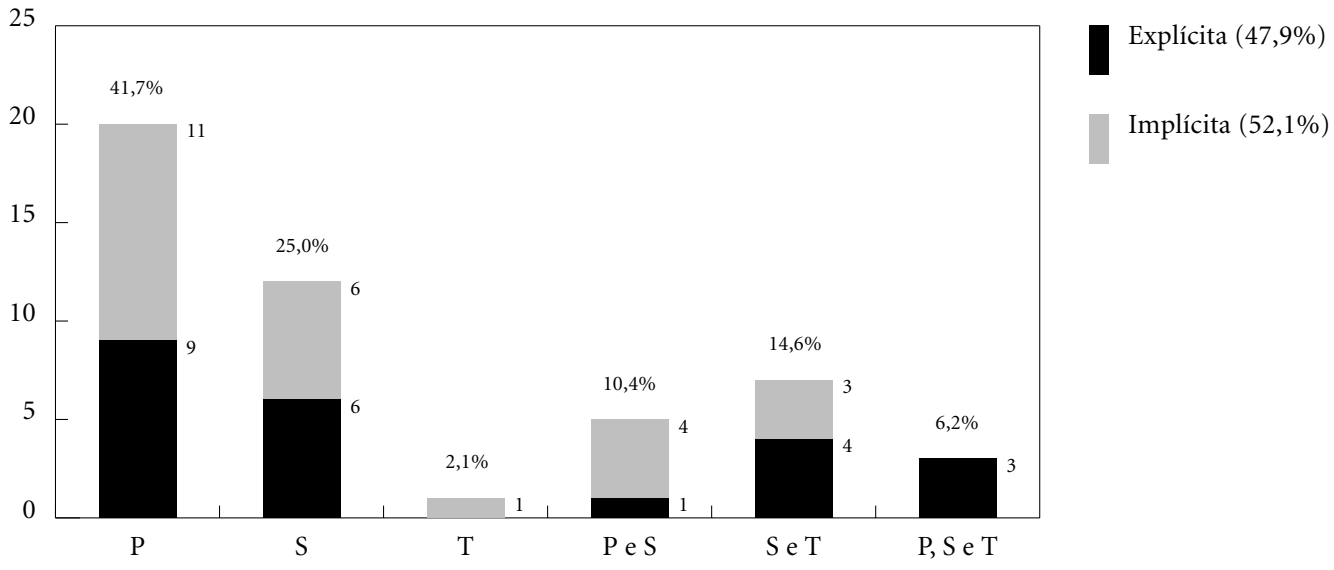

* 1o semestre de 1997 .

$\mathrm{P}=$ primário $\mathrm{S}=$ secundário $; \mathrm{T}=$ terciário. 
Tabela 1

Distribuição dos artigos segundo tipo de violência enfocada, 1990-1997 (primeiro semestre)

\begin{tabular}{|c|c|c|c|}
\hline Tipo de violência & $\mathbf{n}$ & $\%$ & Autores \\
\hline Abuso sexual & 5 & 10,4 & $\begin{array}{l}\text { Bitencourt (1995); Campos et al. (1994); Flores \& } \\
\text { Caminha. (1994); Gomes (1996); Zavasch (1991) }\end{array}$ \\
\hline Acidentes em geral & 2 & 4,2 & Del Ciampo \& Ricco $(1996,1997)$ \\
\hline Afogamento & 1 & 2,1 & Dalaneze (1996) \\
\hline Comportamento agressivo & 1 & 2,1 & Magalhães (1995) \\
\hline Delinqüência & 4 & 8,3 & $\begin{array}{l}\text { Castro (1995); Guagliardi (1990); Lefèvre (1993); } \\
\text { Sudbrack (1992) }\end{array}$ \\
\hline Drogas & 6 & 12,5 & $\begin{array}{l}\text { Bucher (1994); Forster et al. (1992); Godoi et al. } \\
\text { (1991); Gorgulho (1995); Scivoletto et al. }(1996,1997)\end{array}$ \\
\hline Homicídio & 1 & 2,1 & Castro (1993) \\
\hline Prostituição & 2 & 4,2 & Gomes (1994b, c) \\
\hline Suicídio & 2 & 4,2 & Friedrich (1995); Stubbe (1996) \\
\hline Violência doméstica & 12 & 25 & $\begin{array}{l}\text { Barison (1992); Cariola (1995); Centeville et al. } \\
\text { (1997); Davoli \& Ogido (1992); Deslandes (1994a); } \\
\text { Farinatti (1992); Fonseca (1992); Marmo et al. (1995); } \\
\text { Menezes et al. (1996); Minayo \& Assis (1994); } \\
\text { Neumann \& Oliveira (1997); Seibel (1992) }\end{array}$ \\
\hline Violência em geral & 8 & 16,6 & $\begin{array}{l}\text { Assis (1994a); Deccache-Maia (1997); Lefèvre (1992); } \\
\text { Mello (1997); Minayo (1990); Minayo \& Assis (1993); } \\
\text { Nogueira (1994); Sukiennik (1992) }\end{array}$ \\
\hline $\begin{array}{l}\text { Vários (relacionados } \\
\text { à morbidade por } \\
\text { causas externas) }\end{array}$ & 1 & 2,1 & Assis \& Souza (1995) \\
\hline $\begin{array}{l}\text { Vários (relacionados } \\
\text { à mortalidade por } \\
\text { causas externas) }\end{array}$ & 3 & 6,2 & $\begin{array}{l}\text { Lyra et al. (1996); Siqueira et al. (1996); Souza \& Assis } \\
\text { (1996) }\end{array}$ \\
\hline Total & 48 & 100 & - \\
\hline
\end{tabular}

balho. Desse modo, os artigos foram assim classificados: Ensaio (estudo que se baseia unicamente na experiência do autor); Estudo de caso clínico (estudo de casuística); Estudo epidemiológico (estudo de distribuição de determinado fenômeno de saúde/doença em determinado local, espaço e grupo populacional); Estudo quantitativo descritivo (estudo que não envolve metodologia epidemiológica embora trabalhe os dados quantitativamente); Pesquisa qualitativa (estudo etnográfico baseado em trabalho de campo) e Revisão bibliográfica (estudo baseado em consulta bibliográfica). A Figura 2 aponta para a predominância de estudos baseados em revisão bibliográfica (45,8\%).

Quanto à área de produção dos artigos, verificou-se, através da Figura 3, concentração no campo da pediatria $(37,5 \%)$. Essa constatação, em princípio, era esperada uma vez que essa especialidade é a que se dedica exclusivamente à criança e ao adolescente. Outra área que se destacou no conjunto da produção foi a da saúde mental, com 15 artigos, correspondendo a $31,3 \%$.

Relacionando a área de produção com metodologia, observou-se que a revisão bibliográfica foi predominante nos artigos das três áreas de maior número de produção (pediatria, saúde mental e saúde pública/coletiva), seguida do estudo quantitativo descritivo onde foram mais freqüentes as áreas de saúde mental e pediatria.

\section{A prevenção segundo os tipos de violência}

Há artigos que abordam a violência em geral cometida contra a criança e o adolescente, sem se deterem num tipo específico de atos violentos ou enfocando mais de um tipo. Com 
Figura 2

Distribuição dos artigos segundo a metodologia empregada, 1990-1997*.

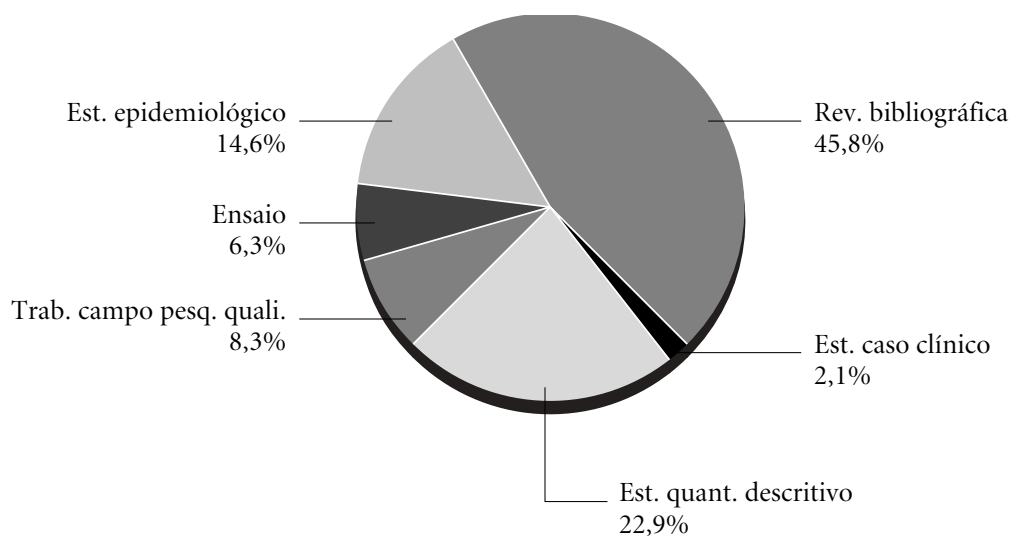

^ 1o semestre de 1997.

Figura 3

Distribuição dos artigos segundo a área de conhecimento, 1990-1997*.

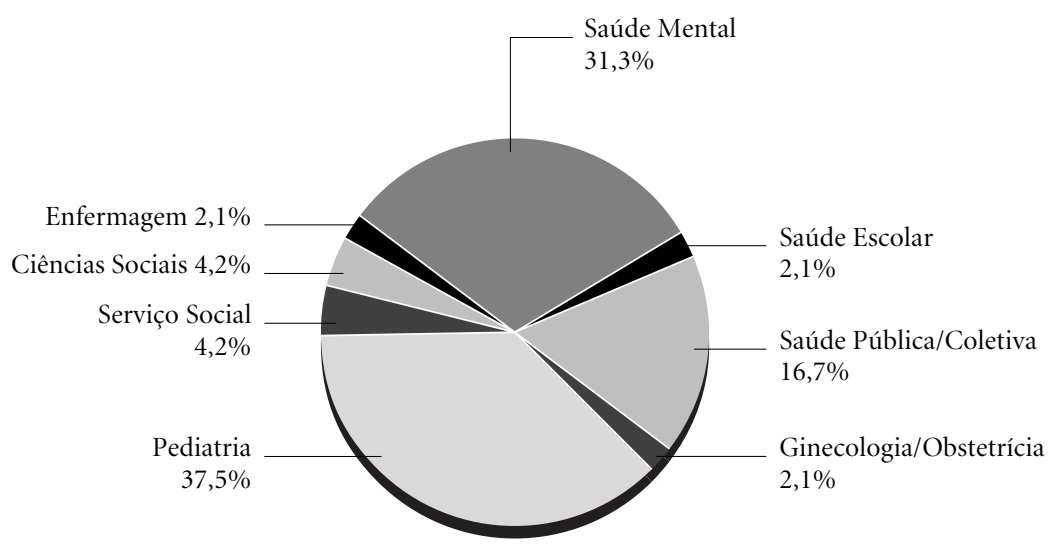

* 1 o semestre de 1997.

base em seus conteúdos, podem ser esboçados princípios que antecedem a elaboração de medidas de prevenção. Assim, tais ações devem ter como ponto de partida: definição de marcos conceituais sobre violência; configuração do quadro dos atos violentos que ocorrem contra as crianças e os adolescentes e suas relações com a realidade social mais ampla; consciência acerca da historicidade da problemática; relação entre maus-tratos e desumaniza- ção; conhecimento dos problemas piscológicos encontrados em crianças que vivem em contato com a violência e articulação com a escola para o desenvolvimento de programas preventivos.

Nesses artigos, em geral, percebe-se que o eixo central da discussão dos princípios de prevenção primária aponta as estruturas e os processos sociais a serem melhor compreendidos para uma atuação incisiva no que se refere à 
violência cometida contra a criança e o adolescente. Nessa discussão sobressaem-se duas tendências. A primeira refere-se ao fato de que a violência não se reduz a ações individuais e, por isso, a prevenção tem que compreender os aspectos bio-psicossociais. A segunda aponta para a necessidade de desconstrução da associação mecânica entre violência, pobreza, criminalidade e violação dos direitos, predominante no senso comum.

Implícita ou explicitamente, os artigos sugerem os seguintes princípios de prevenção:

nivel primário: promoção de condições favoráveis à população para que possa viver qualitativamente melhor; sensibilização e capacitação dos profissionais de saúde para que possam atuar na problemática; participação desses profissionais nos movimentos sociais que se organizam na busca e equacionamento de problemas que afetam direta ou indiretamente a existência de atos violentos; fundamentação das ações em pesquisas estratégicas para que se possa melhor atuar frente aos problemas; construção da cidadania, possibilitando às crianças e aos adolescentes o exercício de seus direitos e deveres;

nível secundário: articulação entre os setores saúde e educação para que se possa melhor identificar ocorrências de maus-tratos e aprimorar diagnósticos que melhor retratem essa ocorrência; estruturação do setor saúde para que possa prestar uma intervenção precoce não só para aqueles que procuram seus serviços como também para os grupos que, apesar de serem alvo da violência, não têm acesso a tais serviços;

nível terciário: organização adequada de serviços de saúde, distribuindo os níveis de atuação que vão desde trabalhos comunitários até serviços de emergência; promoção de modelos de atendimento integral a crianças e adolescentes, que visem não apenas o tratamento dos ferimentos, mas também os problemas psíquicos e sociais, fazendo encaminhamentos necessários, através de equipes multidisciplinares.

Em relação à violência doméstica, a partir dos conteúdos relativos a estratégias que possam incidir na busca de superação, foram esboçados os três níveis de prevenção.

Quanto à prevenção primária destacam-se as seguintes recomendações: a) discussões acerca da temática envolvendo instituições, grupos e meios de comunicação de massa para o conhecimento e sensibilização do fenô- meno; b) discussão, junto a grupos de pais, sobre as diferenças entre disciplina e uso da violência na educação dos filhos; c) promoção de ações de sensibilização dos profissionais de saúde para a problemática. Depreende-se dessas recomendações que ainda há uma falta de reconhecimento da violência que ocorre no âmbito doméstico na população em geral e para os próprios profissionais da saúde. As fronteiras entre os procedimentos educativos e atos violentos nem sempre são facilmente visíveis. Nessa discussão, deve ser repensado o estatuto de ser criança na sociedade que ainda é predominantemente adultocêntrica.

No âmbito da prevenção secundária, ressaltam-se advertências sobre a necessidade de: a) desenvolver uma atitude de suspeita frente às lesões constatadas nas crianças, à indiferença dos responsáveis diante do que aconteceu com o filho que está sendo atendido, e diante da contradição entre o fato narrado pelos responsáveis e os achados clínicos; b) formular diagnósticos ampliados, contemplando diferentes procedimentos. Subentende-se nas recomendações dos autores a necessidade de capacitação dos profissionais de saúde para que possam detectar e dar um pronto atendimento aos casos de violência doméstica que chegam aos serviços. Percebe-se também que a clínica deve ocorrer sob olhares disciplinares distintos.

No que se refere à prevenção terciária, apenas um artigo (Cariolas, 1995) menciona que um serviço faz tratamento e reabilitação de vítimas de violência doméstica e outro (Deslandes, 1994a) recomenda que sejam promovidas as seguintes ações para casos já identificados: a) criação de uma rede de atuação, envolvendo vários serviços e instituições; b) utilização de visitas domiciliares como estratégia de ação; e c) deslocamento da criminalização das famílias para o investimento na atenção a elas. Em geral, parece que a produção é mais incipiente nesse nível de prevenção, indicando que, antes de se esboçar propostas nesse âmbito, ainda há muito a fazer no campo da educação/sensibilização (nível primário) e refinamento de diagnóstico (nível secundário).

Junto à categoria de violência doméstica, há outra que se dirige para os acidentes em geral que ocorrem principalmente no lar da criança. Os artigos que tratam desses acidentes (Del Ciampo et al., 1996, 1997) apontam para a necessidade de os programas de preven- 
ção se basearem em estudos regionalizados para que possam ser implantadas ações mais direcionadas, a fim de que acidentes com crianças sejam evitados. Os autores também destacam a importância de se incorporar na prática da pediatria a discussão, orientação e divulgação de preceitos básicos em prevenção de acidentes junto aos seus pacientes.

Vários artigos assinalam que a ocorrência de acidentes com crianças em seus lares deve ser mais refletida. Não resta dúvida de que nem todos os acidentes se caracterizam como violência doméstica. No entanto, não se pode deixar de lado a possibilidade de um "acidente" camuflar um ato violento. Ampliando mais a reflexão, pode-se pensar que, por trás de um acidente, pode estar presente um tipo de negligência.

Em relação à droga, faz-se necessário observar que sua inclusão, neste trabalho, no rol dos tipos de violência relacionados à criança e ao adolescente deveu-se ao fato de, entre outros aspectos, o seu uso ser considerado uma violência contra o desenvolvimento bio-psicossocial; seus usuários podem ser alvos fáceis para grupos de exploração e o consumo pode potencializar atos de delinqüência.

No conjunto dos artigos que tratam do uso de drogas, ressalta-se, de forma implícita e explícita, as prevenções primária e secundária. No primeiro nível, logo de início, destaca-se a necessidade de se promover medidas educativas junto à população em geral e a grupos de crianças e adolescentes frente ao fato de que a iniciação ao uso de álcool, fumo e inalantes ocorre precocemente. Entre a população-alvo das ações de cunho educativo, meninos e meninas que vivem na rua e escolares devem ser a clientela prioritária dos programas de prevenção primária, segundo alguns autores. Em meio às recomendações, Bucher e colaboradores (1994) propõem que a discussão da relação entre consumo de drogas e desenvolvimento da delinqüência juvenil seja enfocada a partir do pressuposto de que ambos são conseqüências de determinadas situações sociais que se opõem aos valores humanos fundamentais. Segundo os autores em questão, com esse debate deve-se buscar uma revalorização da vida para a promoção de uma cultura preventiva na sociedade.

As propostas dos artigos, em geral, contemplam a idéia de que o combate ao uso de drogas não deve ser reduzido às informações dos males que ela causa, mas deve ser amplia- do para instâncias macro-sociais que, de uma forma ou de outra, se associam a tal uso.

A prevenção secundária, no que se refere ao diagnóstico de uso de droga, em geral está direcionada para a necessidade de se distinguir o uso experimental ou recreacional da dependência. Essa diferenciação permitiria referenciar para serviços especializados e nortear tratamentos específicos. Outra distinção necessária, segundo os autores, se refere àquela que separa os quadros de dependência dos depressivos.

A prevenção da violência sexual nos artigos analisados trata predominantemente do nível secundário. Apenas um artigo (Gomes, 1996) fica exclusivamente no nível da prevenção primária, apontando princípios em termos de informações que deveriam ser veiculadas para a população acerca do problema e reflexões sobre formas de melhor prevenir atos de violência sexual a grupos mais expostos, como é o caso de meninas que vivem na rua. Outro artigo (Campos et al., 1994), embora aborde a prevenção secundária, indica também que, em termos de nível primário, haja esclarecimento à população sobre a importância de a denúncia ser realizada logo após a agressão sexual para que os indícios não se desfaçam com o tempo. Esse artigo também observa que seja disseminada a idéia de que qualquer omissão de denúncia de maus-tratos a crianças e adolescentes é crime passível de punição.

No nível secundário, o núcleo central gira em torno da idéia de melhor se aprimorar o diagnóstico para que se possa detectar a presença do abuso sexual, sua extensão e a intervenção adequada. Propõe-se que a deteç̧ão não seja realizada apenas através de entrevistas. Exames clínicos para casos específicos, como os de utilização de colposcópio; atividades que envolvam desenhos quando a vítima for criança e a observação das condutas de quem está sendo examinado são algumas estratégias sugeridas. No que se refere à avaliação do agressor, Bittencourt (1995) adverte que não se deve reduzir a análise a uma patologização, fazendo com que o ato agressivo seja "compreensivo", podendo desencadear um processo em que a criança passa de vítima a ré.

A prevenção terciária se encontra implícita em dois artigos (Zavaschi, 1991, Bittencourt, 1995). No primeiro, podem ser deduzidas as seguintes idéias: a) a reabilitação da vítima deve tomar como princípio o fato de que as pessoas dispõem de potencial para se reorganizar 
em frente a experiências traumáticas, e b) o tratamento deve ser multidisciplinar. Já o segundo observa que se deve proteger a criança das possíveis "retaliações", após a descoberta do abuso.

Em geral, os artigos que tratam da questão da delinqüência propõem, no que se refere ao nível primário, que sejam detectadas as linhas de força configuradas nas representações sociais correntes sobre "criança-bandido" e que sejam estudadas as relações entre delinqüência, interações familiares e interações sociais mais amplas.

No nível secundário, destacam que a condição de escuta e ajuda devem ser promovidas para que se possa avaliar o que ocorre por detrás do que é rotulado por delinqüência, evitando-se, assim, endossar um proselitismo ideológico que desconsidera a possibilidade dos atos delinqüentes serem reações a um sistema social injusto. Ainda nesse nível, devem ser promovidos diagnósticos para que sejam diferenciados os atos isolados de comportamentos anti-sociais de distúrbios mentais.

Em termos de nível terciário, deve-se evitar o efeito perverso de se ter uma intervenção tão ou mais violenta que os atos julgados violentos. As ações desse nível, segundo os autores, devem sobretudo ser de caráter educativo e não punitivo, articulando-se com as famílias e trabalhando contra a estigmatização.

No que tange ao suicídio, um dos artigos (Stubbe, 1996) apresenta uma proposta de prevenção dividida em três fases: prevenção geral, intervenção em crises e tratamento posterior. Na primeira fase não se deve levar em conta somente a suspeita do risco de suicídio, mas também a superação de suas causas, atuando-se nas condições familiares de forma a promover o desenvolvimento de uma pessoa otimista, consciente de si e com sentimentos sociais. A esses esforços, somam-se outros que extrapolam o meio familiar: a eliminação na sociedade de atitudes que promovam o suicídio, como a condenação e o tabu que giram em torno dele; a luta contra o individualismo extremo; o combate à idéia do suicídio como última liberdade do homem e salvação de honra. A intervenção frente às crises se relaciona aos esforços empreendidos para se evitar uma eminente tentativa de auto-destruição e salvar a vida após tal tentativa, tendo como prioridade a integridade física. O tratamento posterior, que intervém no campo psíquico, deve ser seguido sem interrupção e, como forma ideal, incorporar as pessoas mais importantes do relacionamento da criança e do adolescente. É importante desenvolver terapia em grupo para que se possa quebrar o isolamento e promover a comunicação.

O outro artigo (Friedrich, 1995) avança no sentido de melhorar a avaliação dos riscos de suicídio entre crianças, destacando que devem ser observados os seguintes dados: tentativa de suicídio anterior; perda recente de figuras significativas em seu relacionamento; baixo limite de resistência frente à frustração; morte de pessoas próximas; preocupação exagerada com a morte; tentativa de suicídio de pessoas próximas e acidentes freqüentes.

No que se refere à prostituição infanto-juvenil, no conjunto das obras, só há dois artigos que abordam tal problemática (Gomes, 1994b, c). Em termos de prevenção primária, recomenda-se que a saúde pública se articule inicialmente com outros setores para atuar frente a essa realidade complexa, partindo da compreensão do universo familiar e das questões estruturais relacionadas a essa problemática.

Percebe-se que a produção que aborda esse tipo de violência se dedica mais para o conhecimento dessa problemática que para a prevenção. Ficou constatado que pouco se produziu acerca do assunto, uma vez que os dois textos analisados pertencem a um único autor e se baseiam em uma única pesquisa. Assim, em termos de prevenção, ainda há muito a amadurecer nos estudos empíricos e teóricos para que se possam esboçar recomendações.

Os artigos que tratam de prevenção da mortalidade por vários tipos de violência, baseados em estudos quantitativos, esboçam estratégias que possam evitar as mortes violentas. No caso dos acidentes de trânsito, sugerese que os programas não só se dirijam para a segurança dos carros e de seus ocupantes, mas também contemplem os pedestres. Torna-se importante, ainda, o desvelamento das estatísticas de mortalidade para que se possa distinguir as que são homicídios e suicídios, bem como a compreensão dos antecedentes dessas mortes. Por último, propõe-se que os programas sejam pautados no conhecimento das características dos adolescentes, das mudanças sócio-econômicas e dos aspectos comportamentais que propiciam maior risco para a adolescência.

No conjunto da produção estudada, há outros tipos de violência que são abordados por 
apenas um artigo. As idéias acerca de prevenção, contidas implícita ou explicitamente nesses trabalhos, são apresentadas a seguir.

No artigo de Assis e Souza (1995), são esboçados princípios para a prevenção secundária da morbidade por vários tipos de violência. Essa temática não é comum na literatura no campo da saúde e talvez se deva ao fato da precária sistematização de dados. Isso denota que, para se investir na prevenção nesse campo, deve-se investigar mais. O que se destaca na obra em questão diz respeito à idéia de que as ações de prevenção reconhecem os diferentes espaços da violência, tratando-os de forma diferenciada. Assim, se um programa deseja intervir no abuso sexual cometido contra crianças deve voltar suas estratégias para o lar das mesmas, compreendendo esse espaço e atuando com os que dele fazem parte. Com relação aos eventos mórbidos causados por acidentes de trânsito, as autoras recomendam medidas similares, como a priorização dos pedestres, para se prevenir os acidentes fatais.

Há somente um artigo que trata de assassinatos de crianças e adolescentes (Castro, 1993). Isso, no mínimo, causa perplexidade. Se o homicídio é significativo como causa de mortalidade de adolescentes, por que no conjunto de 48 artigos só há um que trata dessa temática de forma específica? Nesta obra o que se recomenda, em termos de prevenção primária, é o investimento na construção dos direitos de cidadania dos segmentos da população que são excluídos e o combate à impunidade para que se possa mudar o quadro dramático de homicídios de crianças e adolescentes.

$\mathrm{O}$ artigo que aborda comportamentos agressivos fornece subsídios para a prevenção primária no sentido de que as condutas não se transformem em violência. Nesse nível, recomenda-se que o ambiente da criança seja o mais rico possível, estimulando a exploração e a brincadeira, e reduzindo a manifestação de elevados níveis de agressão.

Por último, registra-se um artigo sobre afogamento na infância (Dalaneze, 1996). Os princípios de prevenções primária e secundária se referem à recomendação do uso efetivo de travas automáticas seguras em portões e coberturas de piscinas para prevenir acidentes; presteza e persistência na ação contra a insuficiência respiratória; e a utilização de diagnóstico e tratamento precoce adequado da insuficiência respiratória com intubação e ventilação mecânica. O autor não recomenda na- da além de procedimentos voltados para o afogamento em si, mas vale observar que o investimento no campo da prevenção da negligência pode evitar o afogamento.

\section{Conclusão}

Na prevenção à violência contra criança e adolescente há uma gama considerável de material produzido no Brasil que se divide entre dissertações, teses, livros, artigos e manuais. No entanto, pode-se destacar a importância de manuais instrucionais que vêm sendo utilizados por profissionais de diversas áreas (Brasil, 1993; Assis, 1994b; Deslandes, 1994b). Esses manuais procuram adaptar para a realidade brasileira as medidas preventivas que devem ser incorporadas às ações dos setores da saúde e da educação.

É interessante notar que a produção analisada aqui, ou seja, artigos em periódicos, mostram uma tendência do início para o final da década de condução das pesquisas, assim como das propostas de prevenção, para realidades cada vez mais específicas, revelando que o conhecimento acerca da violência tem peculiaridades a serem tratadas, tanto do ponto de vista do indivíduo quanto das condições sócio-econômicas e geográficas em que as crianças e os adolescentes estão envolvidos. De acordo com essa perspectiva, os autores evitam cair na armadilha da medicalização do problema, pleiteando uma compreensão da multicausalidade da violência e não a reduzindo ao plano do indivíduo.

Considerando, portanto, o conjunto de artigos analisados, em geral, todas as propostas dos autores estudados destacam a necessidade de se adotar um trabalho interdisciplinar por parte dos profissionais. Isso significa que nem a saúde nem outro setor consegue, com um só olhar, dar conta da complexidade que é a prevenção da violência contra crianças e adolescentes.

Como apontam todos os artigos, as estratégias de prevenção à violência são extremamente necessárias para que se possa evitar danos graves à saúde desse grupo. Entretanto, sabe-se que não basta pesquisar e publicar se essas estratégias não forem assimiladas pelos profissionais e se o tema da prevenção não for adotado, prioritariamente, pelas políticas públicas que lidam com essa população, a fim de que se possa transformar o conhecimento em 
realidade. Além disso, para se prevenir é preciso, antes de tudo, acreditar na capacidade humana de mudar. Como observa Maldonado (1998), ninguém nasce violento, embora a agressividade faça parte da natureza humana. Assim, a violência pode ser desaprendida. $\mathrm{Pa}-$ ra isso faz-se necessária a promoção de um

\section{Agradecimentos}

Os autores agradecem a Professora Suely Ferreira Deslandes que integra a equipe da pesquisa da qual este artigo faz parte. Agradecem, também, às bolsistas Alessandra Jesus Machado Cruz, Hynajara Boueris da Silva, Janaína dos Santos Soares e Silva e Michele Emanuela D’Abreu Campos, que participaram do levantamento bibliográfico.

\section{Referências}

Assis SG 1994a. Crianças e adolescentes violentados: passado, presente e perspectivas para o futuro. $\mathrm{Ca}$ dernos de Saúde Pública 10(Supl. 1): 126-134.

Assis SG 1994b. Crescer sem Violência: Um Desafio para Educadores. Fiocruz/ENSP/Claves, Rio de Janeiro, $32 \mathrm{pp}$.

Assis SG \& Souza ER 1995. Morbidade por violência em crianças e adolescentes do município do Rio de Janeiro. Jornal de Pediatria 71(6): 303-312.

Bardin L 1979. Análise de Conteúdo. Edições 70, Lisboa, 229 pp.

Barison MS 1992. Famílias envolvidas em situação de maus-tratos contra a criança e o adolescente. Cadernos CBIA 1(4): 39-43.

Bittencourt CBF 1995. Violência sexual contra crianças: implicações psicológicas. Pediatria Moderna XXXI (3): 420-424.

Brasil 1993. Violência Contra a Criança e o Adolescente: Proposta Preliminar de Prevenção e Assistência à Violência Doméstica. Ministério da Saúde, Brasília, 24 pp.

Bucher R, Doneda D \& Carmo RA 1994. Acerca da delinqüência juvenil e consumo de drogas. Psicologia: Teoria e Pesquisa 10(2): 287-297.

Campos JR, Nascimento LG, Almeida Jr. WJ, Vaintraub MT, Silva HMS \& Lopes GP 1994. Violência sexual em Belo Horizonte, pesquisa no Instituto Médico Legal. Jornal Brasileiro de Ginecologia 104(7): 227-230.

Cariola TC 1995. A posição da criança vítima de maustratos na constelação familiar. Pediatria Moderna XXXI(2): 158-162.

Castro HML 1995. Transtorno de conduta em crianças e adolescentes de rua no Brasil. Jornal Brasileiro de Psiquiatria 44(8): 403-409.

Castro MMP 1993. Assassinatos de crianças e adolescentes no estado de São Paulo. Revista Crítica de Ciências Sociais 36(fev.): 81-102. programa de prevenção envolvendo ações governamentais e civis conjuntas, para que as pessoas possam "criar um clima harmônico em seus relacionamentos e fortalecimento dos sentimentos de compaixão e de solidariedade (...) para o estabelecimento da Cultura da Paz" (Maldonado, 1998: 116).
Centeville M, Cabral MAA \& Atadia SA 1997. Incidência e tipos mais freqüentes de castigos aplicados pelos pais ou responsáveis a escolares na cidade de Campinas-SP. Pediatria Moderna XXXIII(3): 99105.

Dalaneze MC 1996. Afogamento na infância. Pediatria Moderna XXXII(3): 282-287.

Davoli A \& Ogido R 1992. A negligência como forma de violência contra a criança e a importância da atuação médica. Jornal de Pediatria 68(11/12): 405408.

Deccache-Maia E 1997. Pobreza, crime e trabalho. Boletim Técnico do Senac 23(2): 13-21.

Del Ciampo LA \& Ricco RG 1996. Acidentes na infância. Pediatria 18(4): 193-197.

Del Ciampo LA, Ricco RG \& Muccillo G 1997. Acidentes domésticos na infância na área de Vila Lobato ( $\mathrm{Ri}$ beirão Preto - SP). Pediatria 19(1): 38-42.

Deslandes SF 1994a. Atenção a crianças e adolescentes vítimas de violência doméstica: análise de um serviço. Cadernos de Saúde Pública 10(Supl. 1): 177187.

Deslandes SF 1994b. Prevenir a Violência: Um Desafio para Profissionais de Saúde. Fiocruz/ENSP/Claves, Rio de Janeiro, 39 pp.

Farinatti FAS 1992. A criança maltratada. Revista Pesquisa Médica 26(2): 47-50.

Flitcart A 1993. Physicians and domestic violence: challenges for prevention. Health Affairs 12: 154-160.

Flores RZ \& Caminha RM 1994. Violência sexual contra crianças e adolescentes: algumas sugestões para facilitar o diagnóstico correto. Revista de Psiquiatria 16(2): 158-167.

Fonseca NM 1992. O assistente social e a intervenção nas situações de violência. Revista Pesquisa Médica 26(2): 53-54 
Forster LMK, Barros HMT, Tannhauser SL \& Tannhauser M 1992. Meninos na rua: relação entre abuso de drogas e atividades ilícitas. Revista ABP-APAL 14(3): 115-120.

Friedrich S 1995. Suicídio na infância. Pediatria Moderna XXXI(2): 226-231.

Godoi AMM, Muza GM, Costa MP \& Gama MLT 1991. Consumo de substâncias psicoativas entre estudantes de rede privada. Revista de Saúde Pública 25(2): 150-156.

Gomes R 1994a. A análise de dados em pesquisa qualitativa, p. 67-80. In MCS Minayo (org.) - Pesquisa Social: Teoria, Método e Criatividade. Editora Vozes, Petrópolis.

Gomes R 1994b. Prostituição infantil: uma questão de saúde pública. Cadernos de Saúde Pública 10(1): 58-66.

Gomes R 1994c. A violência enquanto agravo a saúde de meninas que vivem nas ruas. Cadernos de Saúde Pública 10(Supl. 1): 156-167.

Gomes R 1996. Processo saúde-doença ligado à sexualidade de meninas que vivem na rua. Revista LatinoAmericana de Enfermagem 4(1): 163-176.

Gorgulho M 1995. Uso de drogas: conceitos e preconceitos. Pediatria Moderna XXXI(6): 1014-1016.

Guagliardi EC 1990. Um lugar de violência. O lugar da psiquiatria. Hegemonia, identidade e prática. Jornal Brasileiro de Psiquiatria 39(2): 85-90.

Leavell HR \& Clarck EG 1976. Medicina Preventiva. McGraw-Hill, São Paulo.

Lefèvre F 1992. Violação e violência: resgatando a violação como fato cultural. Revista Brasileira de Crescimento e Desenvolvimento Humano II(2): 36-42.

Lefèvre F 1993. Esta criança é um bandido! Este bandido é uma criança! Revista Brasileira de Crescimento e Desenvolvimento Humano III(2): 71-77.

Lyra SMK, Goldenberg T \& Iyda M 1996. Mortalidade de adolescentes em área urbana da região sudeste do Brasil, 1984-1993. Revista de Saúde Pública 30(6): 587-591.

Magalhães CMC 1995. Agressão em crianças: influência de sexo e de variáveis situacionais. Psicologia: Teoria e Pesquisa 11(1): 7-12.

Maldonado MT 1998. Caminhos da prevenção da violência doméstica e escolar: construindo a paz. Adolescência Latinoamericana 1(2): 111-117.

Marmo DB, Davoli A \& Ogido R 1995. Violência doméstica contra a criança (parte I). Jornal de Pediatria 71(6): 313-316.

Mello YB 1997. Problemas psicológicos encontrados em crianças que vivem em contato constante com a violência: um depoimento. Estudos de Psicologia 2(1): 140-160.

Menezes MGP, Oliveira MCJ, Osmo AA, Setin SMC, Spinelli MA, Pahl MMC, Gilio A, Lotufo JPB, Ejzenberg B, Baldacci ER \& Okay Y 1996. A criança vítima de maus tratos atendida em serviços de emergência. Pediatria 18(2): 75-81.

Minayo MCS 1990. A violência na adolescência: um problema de saúde pública. Cadernos de Saúde Pública 6(3): 278-292.

Minayo MCS \& Assis SG 1993. Violência e saúde na infância e adolescência: uma agenda de investigação estratégica. Saúde em Debate 39(jun.): 58-63.

Minayo MCS \& Assis SG 1994. Saúde e violência na infância e na adolescência. Jornal de Pediatria 70(5): 263-266.
Minayo MCS \& Sanches O 1993. Quantitativo-qualitativo: oposição ou complementaridade? Cadernos de Saúde Pública 9(3): 239-262.

Neumann MM \& Oliveira MCF 1997. Violência doméstica contra crianças e adolescentes: notificações recebidas pelo centro de atenção aos maus tratos na infância. Psicólogo Informação 1(1): 37-48.

Nogueira MA 1994. O papel da escola na prevenção dos maus-tratos na infância e adolescência. Revista Brasileira de Saúde Escolar 3(1-4): 241-243.

Scivoletto S, Henriques Jr. SG \& Andrade AG 1996. A progressão do consumo de drogas entre adolescentes que procuram tratamento. Jornal Brasileiro de Psiquiatria 45(4): 201-207.

Scivoletto S, Henriques Jr. SG \& Andrade AG 1997. Uso de drogas por adolescentes que buscam atendimento ambulatorial: comparação entre crack e outras drogas ilícitas - um estudo piloto. Revista ABP-APAL 19(1): 7-17.

Seibel H 1992. Dinâmica dos maus tratos à criança; características do adulto maltratante e da criança maltratada; o maltrato como perturbação do vínculo mãe-filho. Revista Pesquisa Médica 26(2): 51-52.

Siqueira AAF, Tanaka ACA, Alvarenga AT \& Schor N 1996. Perfil da mortalidade de mulheres de 10 a 19 anos na região sul do município de São Paulo. Revista Brasileira de Crescimento e Desenvolvimento Humano 6(1/2): 69-76.

Souza ER \& Assis SG 1996. Mortalidade por violência em crianças e adolescentes do município do Rio de Janeiro. Jornal Brasileiro de Psiquiatria 45(2): 8594.

Stubbe H 1996. Suicídios e tentativas de suicídio de crianças. Psicologia Clínica 7(7): 97-118.

Sudbrack MFO 1992. Da falta do pai à busca da lei - o significado da passagem ao ato delinqüente no contexto familiar e institucional. Psicologia: Teoria e Pesquisa 8(Supl.): 447-457.

Sukiennik PB 1992. Alguns aspectos sobre a desumanização, e os maus-tratos, na infância e adolescência. Revista Pesquisa Médica 26(2): 55-58.

Zavasch MLS, Quinalha AF, Enk I, Telelbom M \& Defavery R 1991. Abuso sexual em crianças: uma revisão. Jornal de Pediatria 67(3/4): 130-136. 